\title{
Adoption of Online Network Tools by Minority Students: The Case of Students of Ethiopian Origin in Israel
}

\author{
Meital Amzalag \\ University of Haifa, \\ Haifa, Israel \\ meital@ruppin.ac.il
}

\author{
Nelly Elias \\ Ben-Gurion University of the \\ Negev, Beer Sheva, Israel \\ enelly@bgu.ac.il
}

\author{
Yael Kali \\ University of Haifa, Haifa, Israel
}

yael.kali@gmail.com

\begin{abstract}
Students of Ethiopian origin belong to one of the weakest sectors in the Jewish population of Israel. During their studies they have to deal with social alienation, cultural gaps, economic hardships, and racial stereotypes which reduce their chances to successfully complete their academic degree. In this respect, the present research asks whether online social media could provide those youngsters with tools and resources for their better social integration and adaptation to the academic life. For this purpose, the study was conducted in one of Israel's largest academic colleges while adopting a design-based research approach, which advanced gradually on a continuum between 'ambient' and 'designed' technology-enhanced learning communities. The interventions applied for this study aimed at examining how they may encourage students of Ethiopian origin to expand their activities in the online social learning groups. The findings indicate that the main pattern of students of Ethiopian origin online participation was peripheral and limited to viewing only. Nevertheless, the level of their online activity has been improved after a series of two interventions, which also led to a slight improvement in indicators of their social integration and in a change in their usage of online learning groups from social to academic uses.
\end{abstract}

Keywords: students of Ethiopian origin, immigrant' social integration, social media, online learning groups, peripheral participation, Israel

Material published as part of this publication, either on-line or in print, is copyrighted by the Informing Science Institute. Permission to make digital or paper copy of part or all of these works for personal or classroom use is granted without fee provided that the copies are not made or distributed for profit or commercial advantage AND that copies 1) bear this notice in full and 2) give the full citation on the first page. It is permissible to abstract these works so long as credit is given. To copy in all other cases or to republish or to post on a server or to redistribute to lists requires specific permission and payment of a fee. Contact Publisher@InformingScience.org to request redistribution permission.

\section{Introduction}

The present study focuses on students of Ethiopian origin who belong to one of the weakest sectors in the Jewish population of Israel (Saguy \& Chernyak-Hai, 2012). This immigrant community copes on a daily basis with the consequences of its being of different skin color to the majority group, which

\section{Editor: Janice Whatley}

An earlier, shorter version of this paper was presented at the Chais conference 2015, in Raanana, Israel, and included in Y. Eshet-Alkalai, I. Blau, A. Caspi, N. Geri, Y. Kalman, \& V. Silber-Varod (Eds.), Proceedings of the 10th Chais Conference for the Study of Innovation and Learning Technologies 2015: Learning in the Technological Era. Raanana: The Open University of Israel. 
makes it a community of "permanent Olim" (immigrants in Hebrew) in Israeli society (Ben Ezer, 1992), making their integration more difficult (Elias \& Kemp, 2010; Mizrachi \& Herzog, 2012; Ringel, Ronnel, \& Getahune, 2005). Even as they get access to academic studies, young people of Ethiopian origin are faced daily with exclusion and manifestations of racism, which lead to feelings of frustration, alienation, and social isolation (Ringel et al., 2005; Salamon, 2003; Walsh \& Tuval-Mashiach, 2012).

In this context, the research literature has shown that computer-mediated communication may offer an alternative for immigrants to make contact with students from the majority society, since the Internet provides them with cultural and academic resources that are unavailable or inaccessible by other communication means (Bosch, 2009; Cheung, Chiu, \& Lee, 2011; Elias, \& Lemish, 2009; Jürgens, 2012). Moreover, immigrants' utilization of the Internet is aimed not only at information seeking and sharing, but also at building social ties with the majority society, which would not have been possible in an offline reality (Clafferty, 2011; Elias \& Lemish, 2009; Steinfield, Ellison, \& Lampe, 2008).

In addition, several studies on students from the majority society in higher education found positive contribution of social media to the learning process (e.g., Forkosh-Baruch \& Hershkoviz, 2012; Kurtz, 2014). Moreover, in parallel with acquiring academic knowledge via online networks, these students searched for information about their peers and initiated new social relationships (Madge, Meek, Wellens \& Hooley, 2009; Quan-Haase \& Young, 2010).

Yet very little is known about the specific contribution of social media to the integration of immigrant students in the academic life. To fill this gap, the present study examined the Ethiopian students' uses of online social media and the connection between the online participation and social and academic integration. For this purpose, we examined the particular patterns of participation of students of Ethiopian origin in online learning groups, the changes that occurred in these patterns, as well as the change in various indicators for a better integration into the academic life, as a result of a series of minimal interventions designed to encourage them to take a more active part in online learning groups without undermining the spontaneous dynamics of participation.

\section{Immigrants of Ethiopian Origin in Israel}

The Jews of Ethiopian origin arrived in Israel within the framework of the Law of Return (Berhanu, 2005) in two major immigration waves, in 1984 and in 1991. Since their arrival in Israel, these immigrants have had to cope with the difficulties of integration in every sphere of life, due to the wide gap between traditional Ethiopian culture and modern Israeli culture. Their working skills were based in agriculture and handicrafts; most of the families had more than three children; and their general level of education was extremely low, as the majority had been living in small remote villages with no formal educational infrastructure (Goldblatt \& Rosenblum, 2007; Ringel et al., 2005; Walsh \& Tuval-Mashiach, 2012).

Upon arrival, virtually all of the Ethiopian immigrants were directed in bulk into Absorption centers located on the margins of peripheral cities, which isolated them from the majority society and fueled their dependence on the Israeli establishment (Flum \& Cinamon, 2011; Goldblatt \& Rosenblum, 2007; Rosenblum, Goldblatt, \& Moin, 2008; Salamon, 2003; Walsh \& Tuval-Mashiach, 2012). As of today, $62 \%$ of families of Ethiopian origin are still living in cities with a disproportionately large concentration of Ethiopian population (Israel's Central Bureau of Statistics, 2013). The majority (70\%) live in a small number of peripheral settlements, usually classified as of lower-middle to low socio-economic status (Vurgan, 2011).

Due to the combination of their geographic concentration in the periphery and lack of skills suitable for Israel's labor market, first-generation immigrants had a tremendous difficulty with occupational integration (thus remaining constantly unemployed) or worked in blue-collar occupations 
that did not require vocational training (Flum \& Cinamon, 2011). As a result, for more than 20 years Ethiopian immigrants remain Israel's poorest population with $41 \%$ of families below the poverty line, compared to $15 \%$ among the general population (Elias \& Kemp, 2010; Myers-JDCBrookdale Institute, 2012). Although today increasing numbers of young adults of Ethiopian origin are integrating in the Israeli labor market, there are still wide discrepancies in employment rates and wage level between them and the rest of the population (King, Fischman, \& WoldeTsadick, 2012).

In addition, immigrants of Ethiopian origin encountered in Israel a great deal of prejudice and discrimination, as they were labeled 'Blacks' in predominantly white Israeli society (Flum \& Cinamon, 2011; Saguy \& Chernyak-Hai, 2012; Salamon, 2003; Walsh \& Tuval-Mashiach., 2012). The racism against the Ethiopian immigrants is even more pronounced when Ethiopian youths come into contact with native Israeli youngsters during their studies and military service (Walsh \& Tuval-Mashiach, 2012). A recent survey of Ethiopian-origin youth indicated that $73 \%$ of them had encountered racist comments about their origin and skin color; $37 \%$ reported racism in their schools; and 33\% thought that youth outside their community avoid making Ethiopian friends because of their ethnic origin (Elem, 2012). In response, youth of Ethiopian origin have developed a new identity, which was completely strange to them prior to their arrival in Israel and which is based on Afro-American ethnic models (e.g., slang, names, hair and dressing style, and music) (Mendelson-Maoz, 2013; Shabtay, 2003 Walsh \& Tuval-Mashiach, 2012).

\section{Difficulties of Immigrants and Ethnic Minorities in Academic Studies}

Research literature shows that in many multi-cultural societies ethnic minority and immigrant students are faced with great difficulties in their integration in academic studies. For instance, in the United States, $49 \%$ of high school graduates who are not immigrants continue their studies in colleges or in universities, compared to $37 \%$ of Hispanic high school graduates (Song \& Elliott, 2011). Moreover, Afro-American students' scores are significantly lower compared to their white peers, despite the fact that these students work much harder than their counterparts in order to achieve their academic goals. This finding is explained by the fact that Afro-American students are forced to dedicate considerable effort and more time (compared to white students) to developing and applying adaptive skills, such as coping with racism, maintaining a positive self-image, and developing support networks (Green, Marti, \& McClenny, 2008).

In Israel as well, ethnic minorities and immigrants experience fundamental difficulties in higher education (Almagor-Lotan \& Koch-Davidovich, 2011; Mesch, 2012). A most prominent example of this is the Arab minority, which constitutes about $20 \%$ of Israel's population, but their participation in the higher education system is only $12 \%$ (Shaviv, Binstein, Stone, \& Fudem, 2013). The percentage of first-degree graduates among the Arab minority is $9.6 \%$ of the total number of graduates, compared to $87 \%$ Jewish graduates (Israel's Central Bureau of Statistics, 2010). Arab students take longer to complete their first degree studies, with only $36.6 \%$ of those who enroll actually managing to complete the program on schedule, compared to $52.5 \%$ of Jewish students (Israel's Central Bureau of Statistics, 2011). Students of Ethiopian origin experience similar difficulties in their academic studies resulting in their low rate in the undergraduate and graduate programs ( $4.5 \%$ compared to $10.2 \%$ in the general population) (Israel's Central Bureau of Statistics, 2013). In addition, the dropout rate from universities is $19 \%$ among students of Ethiopian origin, compared to $11 \%$ in the rest of the population (Annual Israeli Report of the State Comptroller, 2012).

In order to help students of Ethiopian origin reduce these gaps and complete their academic studies successfully, preparatory tracks with dedicated assistance programs are available in most of 
Israel's institutions of higher education. The purpose of these programs is to address gaps in academic literacy and general knowledge; indeed, about $90 \%$ of students of Ethiopian origin begin their academic studies having first completed a pre-academic preparatory track (Almagor-Lotan \& Koch-Davidovich, 2011). Their benefits notwithstanding, such programs create a separation between students of Ethiopian origin and students from the majority population, which may undermine both the self-image of Ethiopian students (as they are labeled as 'struggling academically') and their chances of social integration into the community of majority students.

\section{Internet and Immigrants}

A key concept for examining the relationship between members of a minority group and their own community, as well as between the minorities and the majority society, is social capital. This notion refers to the characteristics of a social organization, such as networks, norms, and trust, which enable coordination and cooperation among individuals for their mutual benefit (Putnam, 1993). In this regard, Putnam (2001) distinguishes between two categories of social capital: bonding - social relations within a minority community, usually characterized as deep, emotional and intensive; and bridging - connecting with the majority society, usually characterized by loose relations of an instrumental nature.

The literature consistently points to the use of Internet by immigrants as a tool for cultivating a bonding social capital. The Internet helps immigrants to maintain contact with their family and friends in their country of origin, to build friendships with members of their ethnic community in the host country, and preserve their culture of origin (Chen, Choi \& Kay, 2011; Elias \& Lemish, 2009; Mesch, 2012; Peeters \& D’Haenens, 2005; Windzio, 2012). Concurrently, among relatively young immigrants (mostly students and youth), there are indications of creating a bridging social capital: building new social relationships with young people from the majority group and acquiring familiarity with the norms and culture of the host country (Chen et al., 2011; Elias \& Lamish, 2009; Ellison, Steinfield \& Lampe, 2007; Steinfield et al., 2008). In this regard, a study by Elias \& Lemish (2009) of immigrant youth from the Former Soviet Union in Israel shows that they perceived the Internet as a more reliable source of information than local socialization agents, such as teachers or fellow students. At the same time, the Internet also provided them with a wide variety of opportunities to learn about Israeli society in a less threatening environment than direct inter-personal communication.

Most of the previous studies, however, have been conducted before the advent of Web 2.0 tools and new digital technologies, such as smartphones, so that there is a scarcity of research on the utilization of social media by immigrants and ethnic minorities. This lack is especially evident in the context of immigrant youngsters' adaptation into the host society and, particularly, in integration into the academic life.

\section{Patterns of Participation in Online Social Media}

The two fundamental factors that motivate individuals to use social media are the needs for socialization and a sense of belonging (Özgüven \& Mucan, 2013). In this context, the literature suggests that Facebook users who are socially active (upload images, write posts, comment on others' posts, share links to news updates, and so on) tend to have lower levels of loneliness, whereas passive users are characterized by higher levels of loneliness (Tobin, Vanman, Verreynne, \& Saeri, 2015). Likewise, higher levels of interaction among Facebook users have been found to be positively correlated with increased social support and, consequently, a declining loneliness over time (Burke, 2011).

Furthermore, passive behavior on social media ("lurking") is correlated with lower levels of satisfaction and intimacy (Preece, Nonnecke, \& Andrews, 2004; Rau, Gao, \& Ding, 2008; Tobin et 
al., 2015). Lurkers are individuals who participate in social media, but initiate posts rarely, if at all, so their participation is mostly limited to viewing (Nonnecke \& Preece, 2001; Rau et al., 2008; Tobin et al., 2015). A number of reasons were offered for lurkers' passivity, including lack of familiarity with the group's nature and activity, shyness, as well as personal, social, and educational insecurity (Nonnecke \& Preece, 2001; Rafaeli, Ravid, \& Soroka, 2004).

Although lurkers' contribution to group's activity is clearly smaller, they do take part in it. Their participation can be characterized according to Lave and Wenger's (1991) definition of "legitimate peripheral participation", which views certain minor activities that newcomers make within a community as first steps in becoming more experienced members and eventually old timers. Moreover, for certain groups, such as immigrants, peripheral participation is often the only possible mode of participation in online activity, due to language barriers and lack of familiarity with the host cultural norms (Elias \& Lemish, 2009). And yet, since social interactions have been found to make group members feel good about themselves and experience the esteem and support of others, peripheral participants should be encouraged to "de-lurk" and take a more active part in online group activities (Hustad \& Arntzen, 2013).

\section{Students' Utilization of Online Social Media}

In recent years, social media have been perceived not only as a place for leisure and recreational activity, but also as a place where spontaneous, non-formal learning can occur. This type of learning is dynamic and ongoing, as it takes place through discussion, debate, and information sharing processes (Burbules, 2006; Forkosh-Baruch \& Hershkoviz, 2012; LINKS, 2012). Within the framework of a learning online group, students raise content-related questions and answer each other. In addition, as group activity increases, so does the students' commitment to learning (Forkosh-Baruch \& Hershkovitz, 2012). This suggests that on top of the online network's traditional role as a virtual meeting place, it is becoming a platform that facilitates and benefits learning (Bosch, 2009; Meishar-Tal, Kurtz, \& Pieterse, 2012).

Social media offer several learning-related benefits: they are open, free of charge, and not owned by the academic institute. These strengths allow social media to expropriate the centralized institutional control and management of scholarly information and move it into the communal cyberspace. Their main advantage over other discussion settings/environments is the fact that they invoke and encourage response and involvement and enable a dynamics of active participation. Such participation could make it easier for members to disagree with each other, thus making them more willing to make their attitudes and opinions regarding the learning content and not merely to consume information, which is often the case in formal learning environments (Bosch, 2009; Burbules, 2006; Meishar-Tal et al., 2012).

Despite the advantages of online social media as a place for meaningful interaction as well as a resource for non-formal learning, their contribution and utilization have not been studied in the context of immigrant students, who experience particular difficulties in integrating into academic studies. The purpose of the present study is, therefore, to examine the immigrant students' uses of online social media, focusing on students of Ethiopian origin in Israel. In addition, because immigrants may have significant difficulties participating in social media due to insecurity and cultural gaps, the present study incorporated a series of interventions designed to encourage more active participation by immigrant students in online learning groups. For this purpose, the following research questions were articulated:

1. What is the scope and nature of participation by students of Ethiopian origin in online learning groups, and how can a more active participation be encouraged through a minimal intervention that does not undermine the spontaneous nature of participation? 
2. What are the uses of online social media by students of Ethiopian origin, and could such uses be modified by minimal intervention?

3. Does participation in online social media contribute to the indicators for a better integration of students of Ethiopian origin into the academic life and could such contribution be increased by minimal intervention?

\section{Methodology}

The methodology adopted for this study is based on combining two disciplines (communication and education) and incorporating research strategies that characterize social science (studying processes without intervention) with those that characterize learning sciences (examining processes through intervention). Along these lines, the study employs a design-based research approach, which has been especially adapted to this unique integration of the research paradigms of both disciplines.

Design-based research includes several cycles, called 'iterations', of design, enactment, and analysis of the learning with the designed environment, and refinement of the design for the next iteration (Barab \& Squire, 2004; Kali, 2008). Through the characterization of the learning that takes place in each iteration, design-based research enables testing theoretical as well as design conjectures. In this manner, design-based research serves to develop both a theory regarding how people learn in specific contexts and means to support learning in this context (Sandoval, 2014).

As mentioned above, to date no research has been undertaken to examine how students from weakened populations in general, and students of Ethiopian origin in particular, use social media in an academic context. Therefore, in contrast to the design-based method commonly employed in learning sciences - where intervention is introduced already in the first iteration - the present study began by observation without intervention, describing the initial 'zero point' which would be used for later comparisons.

\section{Design}

The study was conducted in one of Israel's largest academic colleges, which offers undergraduate studies in a wide variety of disciplines, from behavioral sciences to economics and accounting. To carry out the study, we chose an annual course in computer skills, which is taught as part of the pre-academic preparatory program that the majority of Ethiopian-origin candidates attend in order to improve their chances of admission to first degree tracks. As one of the researchers is the lecturer in that course, various steps had been taken to address ethical issues, such as an explicit assurance, given both verbally and in writing, that participation or non-participation in the study would not affect the students' final scores; protecting participants' anonymity; allowing students to skip questionnaire items; allowing the deletion of posts and text messages exchanged within the online learning groups, which the students did not wish to share with the researcher; and allowing students to opt out of the study at any stage.

The research population comprised students who emigrated or whose parents emigrated from Ethiopia to Israel during the $1990 \mathrm{~s}$, along with students belonging to the 'majority group', comprising white Jewish students. Altogether 279 students participated in the different stages of the study, out of which 75 were of Ethiopian origin ( 55 women; 20 men), and 204 were members of the majority group (125 women; 78 men; 1 undefined). The average age of both groups was 24 years. Out of the Ethiopian-origin group, nine were born in Israel, while 48 had emigrated as children in the early 1990s (for details see Table 1 below). In addition, we analyzed messages written by the study participants on the Facebook and WhatsApp learning groups. All messages were analyzed, including 464 Facebook posts and 1,343 WhatsApp messages (see Table 2). 
The study included three iterations, which were gradually expanded from describing a natural situation without intervention, through minimal intervention, to a slightly more significant intervention. The rationale for expanding the intervention in such small steps was that such steps would enable us to pinpoint the exact stage at which some change had occurred in the uses of online social media of students of Ethiopian origin, as compared to their situation prior to the intervention. In addition, because the contribution of online social media for integrating students of Ethiopian origin in higher education has not been studied before, finding the most effective intervention entailed a slow and careful progression in the implementation of expanded intervention. The present study therefore advanced gradually on a continuum between 'ambient' and 'designed' technology-enhanced learning communities (Kali et al., 2015). The following is a detailed description of the rationale for applying each of the iterations, the data collection methods, and the participants for which data were collected in each iteration.

\section{Iteration 0: Spontaneous use of social media}

In the first stage, called Iteration 0 , a comprehensive survey was conducted in order to get as accurate as possible picture of the purposes and uses of social media in general, and of online learning groups in particular, by students of Ethiopian origin. We sampled students enrolled in various departments (Behavioral Sciences, Business Management, Economics and Administration, Nursing, and the pre-academic preparatory program) who were in various stages of studies towards a first degree, selecting only classes that were attended by students of Ethiopian origin. The time to fill in the survey questionnaire was about 15 minutes. The survey took place during the 20132014 academic year and included 37 students of Ethiopian origin and 136 students from the majority group (see Table 1).

Another source of data was the activity of pre-academic preparatory program students in the WhatsApp and Facebook online learning groups, used in conjunction as students were simultaneously active in both groups. The Facebook group was established for the entire range of courses taught in the program, whereas the WhatsApp group had been opened for the course in mathematics. At the end of the semester, one of the researchers asked permission to join these groups in order to analyze their contents. In total, 318 Facebook posts and 488 WhatsApp messages were analyzed (see Table 2).

\section{Iteration 1: Online learning group participation and uses following minimal intervention}

In the second stage of the study, Iteration 1, we introduced a minimal intervention which consisted of a talk initiated by one of the researchers (who is also a lecturer in the program) with the students regarding the educational value of establishing a learning group on an online social network in the context of the course that she taught. The lecturer told the students that in previous years, students have assessed such groups to be highly conducive to their learning processes. Through that talk, students were exposed to the existence and benefits of such a possibility. At the end of the course, the students permitted the researcher to join their Facebook group and analyze its posts. A total of 146 posts were analyzed (see Table 2).

It should be noted that students who took part in Iteration 1 had also been included in Iteration 0 , which meant that we already had data about them and their patterns of participation in online social networks from the survey questionnaire. Consequently, we did not conduct another survey after this iteration, since the intervention had been minimal and we did not expect to find essential attitude shifts or changes in indicators of social integration compared to those reported in the survey taken in Iteration 0 . The changes that we did expect to find were in the level of participation in the online learning groups, which were assessed using content analysis of their Facebook posts and WhatsApp messages. 


\section{Iteration 2: Online learning group participation and uses following a slightly more significant intervention}

In the third stage, Iteration 2, we expanded our intervention by asking the students to establish a learning group on any social media network (this time as part of the course's requirements) and to allow the researcher to join the group from its inception, as part of the initial intervention. This iteration took place during the 2014-2015 academic year, involving a new group of students who had not participated in Iterations 0 and 1 (see Table 1). The students were free to choose among the various social media platforms, and they opted to establish a WhatsApp group. Similar to previous iterations, at the end of the intervention we analyzed the contents of all 855 messages written by members of the online learning group (see Table 2 ).

In addition, we conducted a survey aimed at pinpointing the uses of online learning groups that have been previously identified in Iteration 0 , as well as an in-depth examination of various indicators that may predict better integration in the academic studies, such as the students' relationships with their peers, social support, sense of self-confidence, assessment of learning difficulties, and self-perceptions regarding academic aptitude (Bettencourt, Charlton, Eubanks, Kernahan \& Fuller, 1999; Yu \& Shen, 2012). This survey was conducted at the beginning and at the end of the iteration, in order to explore the possibility that some of the indicators had changed following the intervention.

Table 1: Participants in each of the iterations

\begin{tabular}{|c|c|c|c|c|}
\hline & \multicolumn{2}{|c|}{ Iteration 0} & \multirow{2}{*}{\begin{tabular}{|l|}
\multicolumn{1}{|c|}{ Iteration1 } \\
Group 2: \\
Facebook learning \\
group \\
$(\mathrm{N}=29)$
\end{tabular}} & \multirow{2}{*}{$\begin{array}{l}\quad \text { Iteration } 2 \\
\text { Group 3: } \\
\text { WhatsApp learning } \\
\text { group } \\
(\mathrm{N}=28)\end{array}$} \\
\hline & $\begin{array}{l}\text { General group } \\
(\mathrm{N}=173)\end{array}$ & $\begin{array}{l}\text { Group 1*: } \\
\text { Facebook }(\mathrm{N}=30) \\
\text { and WhatsApp } \\
(\mathrm{N}=20) \text { spontane- } \\
\text { ous learning } \\
\text { groups } \\
(\text { Total } \mathrm{N}=50)\end{array}$ & & \\
\hline $\begin{array}{l}\text { Students of } \\
\text { Ethiopian } \\
\text { origin }\end{array}$ & $\begin{array}{l}37 \\
(25 \text { women }-68 \% \text {, } \\
12 \text { men }-32 \%)\end{array}$ & $\begin{array}{l}12 \\
(9 \text { women }-75 \%, 3 \\
\text { men }-25 \%)\end{array}$ & $\begin{array}{l}6 \\
(4 \text { women }-67 \%, 2 \\
\text { men }-33 \%)\end{array}$ & $\begin{array}{l}20 \\
(17 \text { women }-85 \% \text {, } \\
3 \text { men }-15 \%)\end{array}$ \\
\hline $\begin{array}{l}\text { Majority } \\
\text { group }\end{array}$ & $\begin{array}{l}136 \\
(90 \text { women }-66 \% \text {, } \\
45 \text { men }-33 \%, \\
1 \text { undefined }-1 \%)\end{array}$ & $\begin{array}{l}38 \\
(17 \text { women }-45 \% \text {, } \\
21 \text { men }-55 \%)\end{array}$ & $\begin{array}{l}23 \\
(11 \text { women }-48 \% \text {, } \\
12 \text { men }-52 \%)\end{array}$ & $\begin{array}{l}8 \\
(7 \text { women }-88 \%, \\
1 \text { man }-12 \%)\end{array}$ \\
\hline
\end{tabular}

* Group 1 is included in the General group

\section{Data Analysis}

\section{Research Question 1: Level of Participation of Students of Ethiopian Origin in the Online Learning Groups}

The objective of Research Question 1 was to examine the scope of activity of students of Ethiopian origin and students of the majority group in online social networks and the changes in this activity following intervention. In analyzing students' activity, we made a distinction between $a c$ tive participation, which was expressed in writing posts/messages, replying to others' posts, and 'likes', versus peripheral participation, which was expressed in reading the responses of other 
students, with little or no writing. All the forms of online activity (which included posts, messages, replies to others' posts, and 'likes') were counted and typed into an Excel spreadsheet, using separate categories for the various iterations and attributing the analyzed contents to students of Ethiopian origin and students of the majority group. We then calculated the average number of posts and messages per student in each of the two groups in order to see whether and how the interventions introduced in the two iterations had affected the participation patterns of students of Ethiopian origins in online learning groups. In addition, we examined the number of students in each of the groups who had not taken any part in the online learning groups in order to ascertain (a) whether and, if so, which iterations had caused changes in the participation pattern of a greater number of students of Ethiopian origin and (b) whether such change was also found in comparison with students of the majority group. The data were analyzed using Excel software (version 2010), including frequencies and averages calculations.

\section{Research Question 2: Utilization of Online Social Networks by Students of Ethiopian Origin}

To examine the different uses of online social networks by students of Ethiopian origin as compared to students of the majority group, we used two complementing research tools: the survey and the content analysis of posts and messages in the online learning groups. In the survey conducted in Iteration 0, we examined the reasons given by students for using Facebook and WhatsApp, while dividing them into three categories: "Learning Uses", "Social Uses" and "Administrative Uses".

The Learning Uses category was examined through questions regarding web use for getting homework-related answers and for receiving study-related materials. The Social Uses category was examined through questions related to the students' utilization of social media for keeping in touch with classmates and for keeping up-to-date with social life in college. The Administrative Uses category was examined through questions regarding the use of social networks for keeping up-to-date with course- and program-related information and instructions, such as lessons locations changes, exercises date of submission. All statements were measured on a four-point Likert scale ( 1 = "strongly disagree" till 4 = "strongly agree"). The survey data were analyzed using SPSS software (version 20), including Independent-samples T Tests, Chi square tests $\left(\chi^{2}\right)$ and frequencies rate calculations.

Concurrently, we attempted to identify the various uses by students of online learning groups through quantifying the qualitative analysis of the verbal data (Chi, 1997) gathered from the Facebook and WhatsApp learning groups. Our analysis indicated that the three categories of use that emerged inductively from students' answers to the open ended questions in the survey (described above) also emerged from the content analysis of the posts and messages in the learning groups. These categories were characterized in this context as follows: Learning Uses (e.g., asking questions, blackboard capture photos, photos of written homework solutions, and notes taken in various classes), Social Uses (e.g., personal and group photos of students, jokes, congratulations), and Administrative Uses (e.g., inquiries and notices about cancelled classes, assignment submission deadlines, and end of semester dates). For each category we examined how many messages and posts were written by students of Ethiopian origin compared to students of the majority group. We then compared the incidence rates of the three categories in each iteration in order to see (a) whether and when a change occurred along the three iterations and (b) whether there was a difference in the activity within the various categories between the two sub-groups (i.e., majority students versus Ethiopian students) and, if so, which iteration had caused that difference. The data were analyzed according to Independent-samples $\mathrm{T}$ Tests procedure. 
Table 2: Research methods in each of the iterations

\begin{tabular}{|c|c|c|c|c|}
\hline Iteration & Type of intervention & Research group & Data corpus & Analysis \\
\hline \multirow[t]{2}{*}{0} & \multirow[t]{2}{*}{ No intervention } & $\begin{array}{l}\text { General group ( } 37 \text { stu- } \\
\text { dents of the minority } \\
\text { group, } 136 \text { students of } \\
\text { the majority group) }\end{array}$ & Survey & $\begin{array}{l}\text { Statistical anal- } \\
\text { ysis }\end{array}$ \\
\hline & & $\begin{array}{l}\text { Group } 1 \\
\text { - } 30 \text { participants in } \\
\text { the spontaneous } \\
\text { learning group on } \\
\text { Facebook ( } 6 \text { stu- } \\
\text { dents of the minori- } \\
\text { ty group, } 24 \text { stu- } \\
\text { dents of the majori- } \\
\text { ty group) } \\
\text { - } 20 \text { participants in } \\
\text { the spontaneous } \\
\text { learning group on } \\
\text { WhatsApp (6 stu- } \\
\text { dents of the minori- } \\
\text { ty group, } 14 \text { stu- } \\
\text { dents of the majori- } \\
\text { ty group) }\end{array}$ & $\begin{array}{l}\text { - } 488 \\
\text { WhatsApp } \\
\text { messages (65 } \\
\text { minority } \\
\text { group, } 423 \\
\text { majority } \\
\text { group) }\end{array}$ & \multirow[t]{2}{*}{$\begin{array}{l}\text { Quantifying } \\
\text { qualitative ana- } \\
\text { lyzes of verbal } \\
\text { data (Chi, } \\
\text { 1997) }\end{array}$} \\
\hline 1 & $\begin{array}{l}\text { Minimal intervention: } \\
\text { Students were told } \\
\text { about the potential } \\
\text { contribution of partici- } \\
\text { pation in a learning } \\
\text { group in social media }\end{array}$ & $\begin{array}{l}\text { Group } 2 \\
\text { - } 29 \text { participants in } \\
\text { the online learning } \\
\text { group on Facebook } \\
\text { (6 students of the } \\
\text { minority group, } 23 \\
\text { students of the ma- } \\
\text { jority group) }\end{array}$ & $\begin{array}{l}\text { - } 146 \text { Face- } \\
\text { book posts } \\
\text { (4 minority } \\
\text { group, } 142 \\
\text { majority } \\
\text { group) }\end{array}$ & \\
\hline 2 & $\begin{array}{l}\text { More substantial inter- } \\
\text { vention: Students were } \\
\text { requested to open a } \\
\text { social media learning } \\
\text { group as part of the } \\
\text { course requirements }\end{array}$ & $\begin{array}{l}\text { Group } 3 \\
\text { - } 28 \text { participants in } \\
\text { the online learning } \\
\text { group on WhatsApp } \\
\text { (20 students of the } \\
\text { minority group, } 8 \\
\text { students of the ma- } \\
\text { jority group) }\end{array}$ & $\begin{array}{l}\text { - } 855 \\
\text { WhatsApp } \\
\text { messages } \\
\text { (355 minori- } \\
\text { ty group, } 500 \\
\text { majority } \\
\text { group) } \\
\\
\text { - Survey } \\
\text { (pre/post) }\end{array}$ & $\begin{array}{l}\text { Quantifying } \\
\text { qualitative ana- } \\
\text { lyzes of verbal } \\
\text { data (Chi, } \\
\text { 1997) } \\
\text { Statistical anal- } \\
\text { ysis }\end{array}$ \\
\hline
\end{tabular}




\section{Research Question 3: Relation between Participation in Online Learning Groups and Integration of Ethiopian Students in Academic Life}

Using the survey conducted at the beginning and the end of Iteration 2, we examined whether there was a change in various indicators of better integration of students of Ethiopian origin in the academic life following the intervention that was designed to promote more active participation in an online learning group. For this purpose, we measured indicators that included the sense of belonging that students felt towards their classmates such as "I feel part of the group"; "I feel alienated from other students in the group"; their satisfaction with their social situation in the preparatory program such as "I am pleased from my social status in the preparatory program", "I feel lonely in the class most of the time" and their sense of self-efficacy such as "I am proud of my academic achievements"; "During studies I feel valuable" and more. Statements were measured on a four-point Likert scale ( 1 = "strongly disagree" to $4=$ "strongly agree"). The surveys data were analyzed using Mann-Whitney test due to a large difference between the sizes of the groups (eight students from the majority group and 20 from Ethiopian origin) and the low number of students from the majority group who participated in the online learning group.

\section{Findings}

\section{Research Question \#1: Level of Participation of Students of Ethiopian Origin in the Online Learning Groups}

The first research question examined the level of participation in online learning groups on social media by students of Ethiopian origin, as compared to students from the majority group and considered how a more active participation may be encouraged through minimal intervention.

As mentioned, Iteration \#0 consisted of examining the students' online activity in two learning groups, one on Facebook and one on WhatsApp. In the Facebook group, the initial nonintervention stage took place during one academic semester, whereas the WhatsApp group continued without intervention for a whole year. Analysis of the online activity of students of Ethiopian origin on the Facebook learning group (six out of the 11 students of Ethiopian origin in the class, see Table 1) shows that during the entire semester they had not initiated any posts, had not responded to any posts written by other students, and had not 'liked' any of the posts or replies by others. In contrast, students from the majority group ( 23 students who were all members of the Facebook group) initiated 28 posts, responded to others' posts 132 times, and 'liked' 87 posts. In semesters of reading the posts and responses, however, there was no difference between students of Ethiopian origin and students from the majority group - every one of the group members had read all the messages.

A slightly different activity pattern was found in the WhatsApp learning group, which was monitored (retroactively) for the entire academic year. All the six students of Ethiopian origin in the class who took this course (six) were members of this online learning group, as well as 12 (out of 14) students from the majority group (see Table 1). During the entire academic year, students of Ethiopian origin wrote 65 messages (an average of nine messages per student), compared to 423 messages written by students from the majority group (an average of 26 messages per student). In addition, only half of the students of Ethiopian origin (three out of six) were active in the group, in contrast to the majority group, in which all members of the online learning group had written messages.

In Iteration \#1 we examined the online activity in the Facebook learning group whose members included six students of Ethiopian origin (out of 11 Ethiopian students in the class and 23 (out of 
26) students from the majority group (see Table 1). The learning group's activity was monitored for one academic semester. As described above, this iteration consisted of a minimal intervention in which the researcher told the students about the academic benefits of joining an online learning group. Our analysis shows that students of Ethiopian origin were scarcely active in the group during entire semester; students of Ethiopian origin initiated only one post, wrote three responses, and 'liked' three posts. Thus, this iteration had not helped in changing their online participation patterns. In contrast, students from the majority group initiated 30 posts, responded 19 times, and 'liked' 60 posts. Nevertheless, as in Iteration \#0, all the posts and responses had been read by all members of the group, regardless of ethnic origin.

Finally, in Iteration \#2, when students were asked to open an online learning group as part of the course's requirements, they chose to open it on WhatsApp. This group included 20 students of Ethiopian origin (out of 21 students in the class) and eight students (out of 14) from the majority group (see Table 1) and was monitored for one academic semester. An analysis of the group's activity shows that students of Ethiopian origin wrote 357 messages (an average of 18 messages per student per semester), compared to 497 messages written by students from the majority group (an average of 62 messages per student per semester). Hence, the findings from Iteration \#2 also indicate an improvement in Ethiopian student's' participation level as compared to Iteration \#0, in which the average number of messages written by students of Ethiopian origin was only nine during the entire academic year (see Table 3).

Table 3: Average number of posts and messages per student in the three iterations

\begin{tabular}{|c|c|c|c|c|}
\hline & \multicolumn{2}{|c|}{ Iteration 0 } & Iteration 1 & Iteration 2 \\
\cline { 2 - 3 } & WhatsApp & Facebook & Facebook & WhatsApp \\
\hline Students of Ethiopian origin & $8.9^{*}$ & $0^{* *}$ & $0.7^{* *}$ & $18.2^{* *}$ \\
\hline Majority group & $26.3^{*}$ & 7 & $2.1^{* *}$ & $61.9^{* *}$ \\
\hline
\end{tabular}

* Average number of posts and mobile messages per student per academic year

** Average number of posts and mobile messages per student per semester

In addition, an improvement was found in online activity among students of Ethiopian origin in the course of the intervention, which was tested for one month near the beginning of the Iteration \#2 and for another month towards its end. Among students of Ethiopian origin, the average number of messages per student increased from the beginning of the iteration (1.5 messages on average) to the period just before the end ( 1.8 messages on average) $\left(t_{(128)}=2.226\right.$, sig<0.05). In contrast, among students from the majority group no change was found in the average number of messages per student in the course of the intervention.

Furthermore, the findings from Iteration \#2 indicate that six out of the 20 online group members of Ethiopian origin did not initiate any messages, whereas all the students from the majority group initiated messages. In addition, five students of Ethiopian origin did not respond to any messages, whereas all of the eight students from the majority group responded to messages posted in the group. Nevertheless, these findings suggest an overall improvement in the participation level of students of Ethiopian origin in online learning groups, since in this iteration, 75 per cent of the students of Ethiopian origin in the class participated in the online activity, whereas in previous iterations, their participation rate had ranged between $0-44$ per cent.

Finally, we should emphasize that because the study was in the research participants' natural environment we had no control over the proportion of students of Ethiopian origin and students 
from the majority group enrolled in different classes selected for the study as well as those who participated in the online learning groups. Moreover, because our interventions were deliberately kept to a minimum, students were given a freedom to make their own choices of different communication platforms (Facebook or WhatsApp). Hence, our analysis yielded two important trends (that were not anticipated in the research design) bearing further implications for the findings presented above.

First, despite an increase in the number of students of Ethiopian origin and a decrease in the number of students from the majority group attending the same class, in Iteration $\# 2$, the majority of the messages (500) were written by students from the majority group in comparison with 355 messages written by the Ethiopian students (see Table 2). This finding is surprising, since being the majority in the online learning group (20 compared to eight), the activity level of students of Ethiopian origin would have supposed to be higher than that of students from the majority group. And second, activity in the Facebook learning group was much more limited in scope compared to the activity in the WhatsApp learning group, both among students of Ethiopian origin and among students from the majority group (see Tables 2 and 3 ).

\section{Research Question \#2: Utilization of Online Social Networks by Students of Ethiopian Origin}

The second research question examined the utilization of online social networks by students of Ethiopian origin, and how (if at all) such uses may change following minimal intervention.

First, it is important to note here that the survey findings collected in Iteration $\# 0$ regarding the students' experience of using online social networks and their access to the technological platforms of Facebook and WhatsApp revealed only minor differences between students of Ethiopian origin and students from the majority group, suggesting that there was no substantial digital divide between the two groups.

Thus, the average number of years of using online social networks among students of Ethiopian origin was 3.3 years, which is slightly lower than among students from the majority group (4 years $)\left(t_{(170)}=3.794\right.$, sig<0.001). Among students of Ethiopian origin, 92 per cent owned a smartphone, compared to 100 per cent among students from the majority group $\left(\mathrm{X}_{(1)}^{2}=11.222\right.$, sig $<0.001)$. Among students of Ethiopian origin, 86.5 per cent had an active Facebook account, compared to 99.3 per cent among students from the majority group $\left(X_{(1)}^{2}=13.959\right.$, sig<0.001). Similarly, 89.2 per cent of students of Ethiopian origin had an active WhatsApp account, compared to 100 per cent of students from the majority group $\left(\mathrm{X}_{(1)}^{2}=15.051\right.$, sig<0.001). Along with these slight differences, there was no significant difference between students of Ethiopian origin and students from the majority group in their frequency of social media usage, as well as in the number of Facebook and WhatsApp groups in which they participated.

On the other hand, the survey findings also suggest that a significantly smaller number of students of Ethiopian origin believed that the online social media contributed to their learning process (52 per cent), compared to students from the majority group ( 78 per cent), $\chi_{(1)}^{2}=7.765, p<0.05$. Differences were also found between students of Ethiopian origin and the majority students regarding specific uses, according to academic, social, and administrative purposes. Thus, students of Ethiopian origin used the online social networks less than students from the majority group for getting help in doing their homework: 2.6 compared to 2.97 , respectively $\left(\mathrm{t}_{(166)}=2.26, \mathrm{p}<0.05\right)$; as well as for studying with their classmates: 2.6 compared to 3.0 , respectively $\left(t_{(166)}=3.086\right.$, sig<0.05). In addition, students of Ethiopian origin used social media less than their majority group counterparts for staying in touch with their classmates and keeping up-to-date in their social life: 2.3 compared to 2.7 , respectively $\left(\mathrm{t}_{(165)}=3.085\right.$, sig<0.05). Finally, differences (albeit statistically insignificant) were also found in the administrative uses, such as keeping up-to-date 
with course requirements and deadlines: 2.6 among students of Ethiopian origin compared to 2.9 among students from the majority group (see Figure 1).

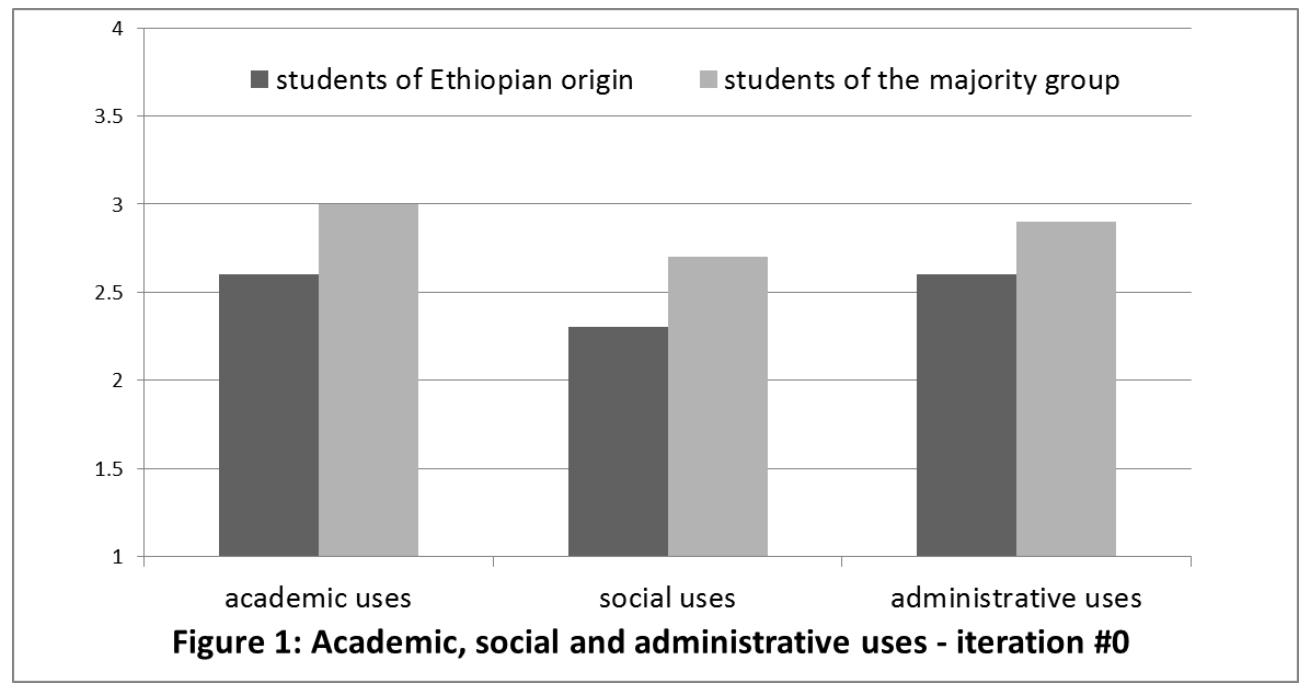

Later on, during Iteration \#2 we examined the actual uses of the WhatsApp learning group, also by categorizing them according to the academic, social, and administrative uses, which were tested for one month near the beginning of the iteration and for another month towards the end of the iteration. The analysis suggests that there was a marked shift from using the online learning group for social purposes to an increased use for academic and administrative purposes. Thus, 61 per cent of all the 'social' messages by students of Ethiopian origin had been written at the beginning of the iteration and 39 per cent at the end. Likewise, 42 per cent of the administrative messages were written at the beginning of the iteration versus 58 per cent at the end; and 100 per cent of all messages for the learning purposes were written at the end $\left(\mathrm{X}_{(2)}^{2}=9.03\right.$, sig<0.01) (see Figure 2$)$.

A quite similar pattern characterized the changes in the majority students toward a more intensive usage of the group for academic purposes and less for the social purposes. Thus, out of the total number of social messages, 64.5 per cent had been written at the beginning of the iteration and 35.5 per cent at the end; and 9.1 per cent of academic messages were written at the beginning of the iteration while 90.9 per cent - by the end. It appears, therefore, that the nature of the WhatsApp learning group had changed in the course of the iteration, with all the students eventually learning to use the group not just for social purposes (such as posting jokes, funny photos, and video clips), but for the academic purposes as well. On the other hand, there was a decrease in the majority students' online group usage for the administrative purposes, since 63 per cent of administrative messages were written at the beginning of the iteration, compared to 37 per cent at the end $\left(\mathrm{X}_{(2)}^{2}=13.34\right.$, sig $\left.<0.001\right)$. 


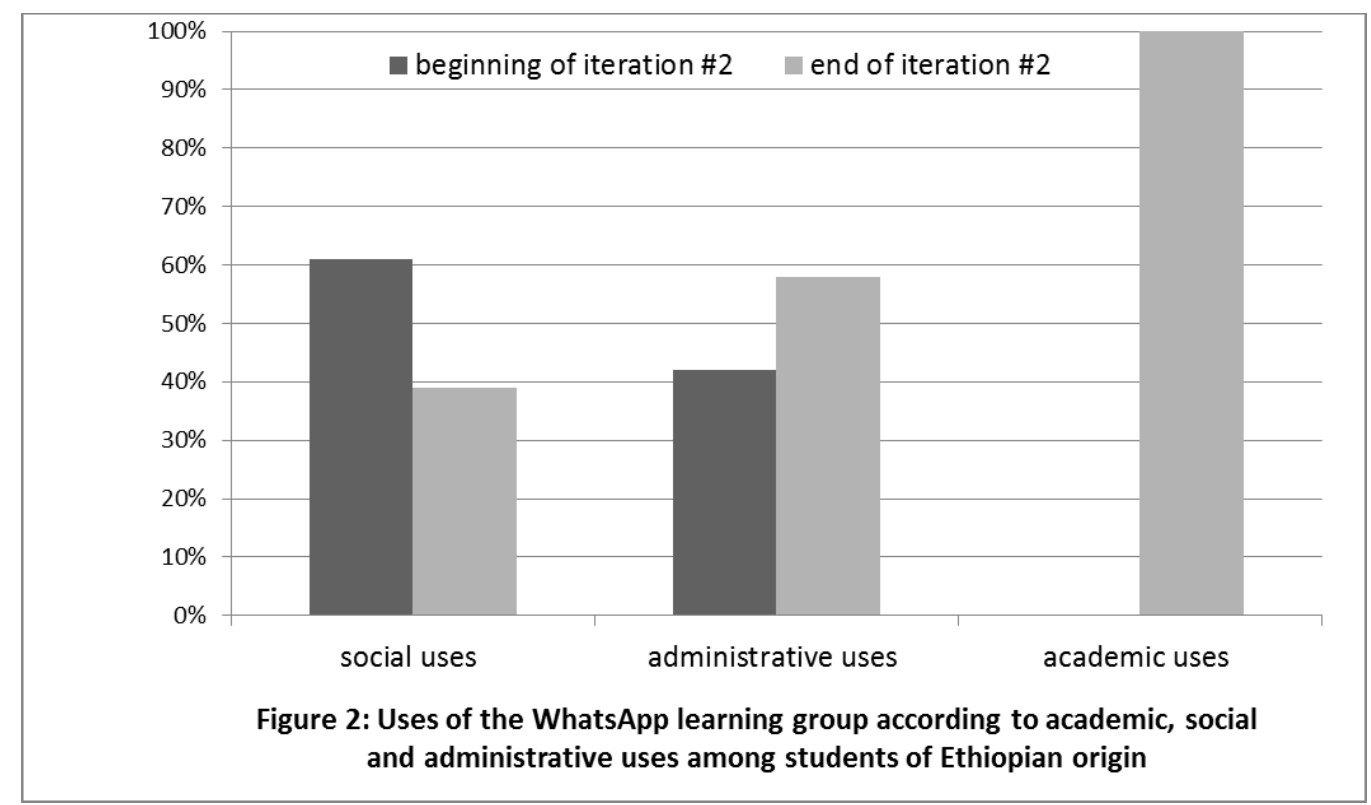

\section{Research Question \#3: Relation between Ethiopian Students' Participation in Online Learning Groups and their Integration in Academic Life}

The third research question examined whether and how participation in online learning groups may improve the integration of Ethiopian students in academic life. Measured indicators included the sense of belonging that students felt towards their classmates, their satisfaction with their social situation during the studies, and their sense of self-efficacy. The findings from the MannWhitney test on students' answers to the two identical surveys (conducted at the beginning and at the end of Iteration \#2) suggest that there was an improvement, albeit statistically insignificant, in some of the indicators of the Ethiopian students' social integration. In particular, by the end of the iteration, students of Ethiopian origin felt that they were more integrated socially than they did in the beginning (from 3.1 to 3.4), whereas among students from the majority group there was no change at all (from 3.3 to 3.3). Moreover, there was a small increase among students of Ethiopian origin in their sense of belonging with students from the majority group (from 3.0 at the beginning to 3.2 at the end), whereas among students from the majority group, there was a decrease in the sense of belonging with students of Ethiopian origin (from 3.4 at the beginning to 3.2 at the end) These light changes can be explained by the fact that the intervention conducted at this stage was so minor that apparently, it was not sufficient to bring about a significant improvement in the quality of online communication between the majority students and their immigrant counterparts.

In parallel, there was a decrease in the indicators measuring self-efficacy among students in both groups. Students of Ethiopian origin felt less confident in their academic aptitude (3.2 at the beginning of the iteration; 2.4 at the end); as did students from the majority group (from 3.3 to 2.8). Nevertheless, there was an overall increase among all the students in semesters of their selfassessment of academic success. That increase was found to be significant among students of Ethiopian origin (from 1.8 at the beginning to 2.3 at the end) $\left(\mathrm{U}_{(32)}=195.50, \mathrm{p}<0.05\right.$ ), but not among students from the majority group (1.9 at the beginning, 2.3 at the end). 


\section{Discussion and Conclusions}

The objective of the present study was to examine the potential of online social networks for improving the integration of students of Ethiopian origin in academic life. This was achieved through a research design in which gradual intervention was introduced in minute steps, designed to encourage a more active student participation in online learning groups.

First and foremost, the study findings suggest that without an intervention the participation pattern of students of Ethiopian origin in the online learning groups was peripheral and limited to viewing only (i.e., 'lurking'). This is in contrast to students from the majority group, who were already active participants in the spontaneous learning groups. This finding is not surprising in light of the fact that youth of Ethiopian origin feel alienated from the host society and suffer from social isolation (Elias \& Kemp, 2010; Ringel et al., 2005).

Following two minimal interventions the activity pattern of students of Ethiopian origin had changed to some extent, and as the level of intervention increased, so did their level of activity in the online learning groups. The more significant change occurred in the course of Iteration \#2, when students of Ethiopian origin began to initiate messages and respond to messages of their peers. It should be noted, however, that despite the interventions, the Ethiopian students' level of online activity was still significantly lower than that of the students from the majority group.

In this context, the study also suggests that the participation pattern of students of Ethiopian origin was not affected by the numerical ratio between them and students from the majority group in the class. When students of Ethiopian origin were a minority, there was a little interaction within the online learning group between them and students from the majority group - a finding that might point to the difficulties in their social integration. When the ratio was reversed, however, and students of Ethiopian origin became a majority in the class, their participation pattern remained peripheral. This finding suggests that the increase in the numerical representation of group members sharing the same cultural background is not sufficient in itself for encouraging students of Ethiopian origin to take a more active part in the online learning activity; instead, planned interventions must be introduced in order to instill the confidence necessary for active participation.

Moreover, the study reveals discrepancies between students of Ethiopian origin and students from the majority group in adoption of the online social networks for academic purposes, such as studying with classmates, homework assistance, and learning from summaries uploaded to the group. Similarly, the analysis of their online activity showed that without intervention most of the uses (albeit very few) have been for social purposes, such as funny pictures and video clips. But when the level of intervention increased, there was a marked increase both in the level of activity and in the academic and administrative uses of the online learning group, along with a decrease in social uses. This finding suggests that social media can be harnessed to the academic needs of students from disadvantaged backgrounds, even without developing and intervening with significant structured activities. This is consistent with the findings of previous studies that examined the learning support afforded by online social networks to students from the majority group (Bansal \& Dhananja, 2014, Kurtz, 2014).

In addition, the findings apparently indicate differences in all students' online activity on different technological platforms (Facebooks versus WhatsApp). Although such differences have not been taken into consideration in the research design, the fact that students were free to choose a different platform in each of the iterations has enabled us to distinguish between patterns of participation on the Facebook and WhatsApp learning groups. While both of the platforms selected by students for creating learning groups have certain common features (such as the ability to deliver group messages, upload pictures, animation, and video clips), each has distinct and unique characteristics that affect its uses (Schejter \& Tirosh, 2014). In addition, WhatsApp being a mobile 
phone application makes it more accessible and easier for students to use it away from home (Bansal \& Dhananja, 2014; Lauricella \& Kay, 2013). Indeed, the research findings suggest that activity in the WhatsApp group was greater in scope and its uses more diverse, although it consisted mostly of short messages accompanied by visual aids (screen shots, photos of assignment solutions, etc.). In contrast, activity in the Facebook learning group was more limited in scope, but the learning opportunities it offered were more comprehensive, as the students uploaded files with class notes, summaries written in preparation for exams, course syllabi, etc.

In parallel with changes that occurred in the scope of online participation and in the utilization of online earning groups by students of Ethiopian origin as the level of interventions increased, there was also an improvement in the indicators of their social integration. That is to say, during Iteration \#2 (following which the Ethiopian students' level of activity in the online learning group had increased), their level of satisfaction from their social situation increased, and their sense of belonging with their classmates was enhanced. Concurrently with the increase in social integration indicators, however, there was a decrease in their self-confidence regarding their academic aptitudes. In our view, however, this finding is not necessarily negative. The research literature shows that learners often experience various difficulties that are regarded as "desirable difficulties" (Bjork \& Linn, 2005) and even localized failures that are defined as "productive failures" (Kapur, 2014). Under certain circumstances, such difficulties and failures could serve as a springboard for the development of further abilities and skills. We intend to examine such circumstances in a further study.

The results of the present study are therefore encouraging, as they suggest that even a minimal intervention, in which students of Ethiopian origin had been required to open an online learning group, has brought about an increase in their active participation, as well as an enhanced utilization of online network tools for academic purposes, and ultimately, a sense of better integration in academic life. We regard this improvement as a first step towards promoting the Ethiopian students' more substantial social involvement and better adaptation to academic life and to Israeli society as a whole. Our findings, however, indicate that access to social media and the skills for using them are in themselves insufficient for creating bridging social capital (Putnam, 2001), because students from disadvantaged background are also faced with social and cultural barriers which apparently prevent their active online participation. Intervention is thus needed in order to encourage a more active and productive intercultural communication in online learning groups, which in turn would facilitate the building of more meaningful social relationships.

Finally, it is important to emphasize the advantages of the methodological design adopted in the present study, integrating methodological approaches that are typical to social sciences with those of education and learning sciences. The shift from studying a phenomenon without intervention (i.e., studying learning in "ambient" technology-enhanced learning environments) into "designed" learning environments, through the use of minute interventionary steps, has enabled us to identify the exact minimal intervention required for affecting the desired changes. A further study should investigate more substantial interventions whilst designing and developing structured activities and moving into designed technology-enhanced learning environments. Such environments would enable us to consider how a more meaningful interaction between students of Ethiopian origin and students from the majority group may be encouraged, in order to continue to improve their social integration within the majority group, and to enhance the self-confidence in their academic aptitude. 


\section{References}

Almagor-Lotan, O., \& Koch-Davidovich, F. (2011). The integration of persons of Ethiopian origin into the higher education system. Jerusalem, Israel: The Knesset, Research and Information. Retrieved from https://knesset.gov.il $/ \mathrm{mmm} / \mathrm{data} / \mathrm{pdf} / \mathrm{me} 02892$.pdf (in Hebrew)

Annual Israeli Report of the State Comptroller. (2012). Aspects promoting the integration of Ethiopian immigrants - Fundamental flaws in the management of national program. Jerusalem, Israel. Retrieved from http://www.mevaker.gov.il/he/Reports/Report 114/926efbcf-6853-4c93-81542844c658d9aa/7917.pdf (in Hebrew)

Bansal, D., \& Dhananjay Joshi, T. (2014). A study of students experiences of WhatsApp mobile learning. Global Journal of Human-Social Science Research, 14(4), 27-33.

Barab, S., \& Squire, K. (2004). Design-based research: Putting a stake in the ground. The Journal of the Learning Sciences, 13(1), 1-14.

Ben Ezer, G. (1992). Like light in a jug: The immigration and absorption of Ethiopian Jews. Jerusalem: Reuven Mass Publishers. (in Hebrew).

Berhanu, G. (2005). Normality, deviance, identity, cultural tracking and school achievement: The case of Ethiopian Jews in Israel. Scandinavian Journal of Educational Research, 49(1), 51-82.

Bettencourt, B. A., Charlton, K., Eubanks, J., Kernahan, C., \& Fuller, B. (1999). Development of collective self-esteem among students: Predicting adjustment to college. Basic and Applied Social Psychology, 21(3), 213-222.

Bjork, R. A., \& Linn, M. C. (2006). The science of learning and the learning of science. APS Observer, 19(3), 1-2.

Bosch, T. E. (2009). Using online social networking for teaching and learning: Facebook use at the University of Cape Town. Communication: South African Journal for Communication Theory and Research, $35(2), 185-200$.

Burbules, N. C. (2006). Self-educating communities: Collaboration and learning through the Internet. In $Z$. Bekerman, N. C. Burbules, \& D. Silberman-Keller (Eds.), Learning in places: The informal education reader (pp. 273-284). New-York: Peter Lang.

Burke, M. (2011). Reading, writing, relationships: The impact of social network sites on relationships and well-being (Unpublished doctoral dissertation). Carnegie Mellon University, Pittsburgh, PA.

Chen, W., Choi, A., \& Kay, S. (2011). Leveraging computer mediated communication for social support in immigrants' intercultural adaptation. Cross-Cultural Communication, 7(3), 167-176.

Cheung, C. M., Chiu, P. Y., \& Lee, M. K. (2011). Online social networks: Why do students use Facebook? Computers in Human Behavior, 27(4), 1337-1343.

Chi, M. T. (1997). Quantifying qualitative analyses of verbal data: A practical guide. The Journal of the Learning Sciences, 6(3), 271-315.

Clafferty, E. M. (2011). Facilitating social networking within the student experience. International Journal of Electrical Engineering Education, 48(3), 245-251.

Elem, youth in distress. (2012). Annual Report for 2012. Bnei Brak, Israel. Retrieved from http://www.elem.org.il/wp-content/uploads/2013/04/\%D7\%93\%D7\%95\%D7\%97\%D7\%A2\%D7\%9C\%D7\%9D-\%D7\%A2\%D7\%91\%D7\%A8\%D7\%99\%D7\%AA-2012\%D7\%A1\%D7\%95\%D7\%A4\%D7\%99222.pdf (in Hebrew).

Elias, N., \& Kemp, A. (2010). The new second generation: Non-Jewish Olim, black Jews and children of migrant workers in Israel. Israel Studies, 15(1), 73-94.

Elias, N., \& Lemish, D. (2009). Spinning the web of identity: The roles of the internet in the lives of immigrant adolescents. New Media \& Society 11(4): 533-551. 
Ellison, N.B., Steinfield, C., \& Lampe, C. (2007). The benefits of Facebook "friends:" Social capital and college students' use of online social network sites. Journal of Computer-Mediated Communication, 12 (4), 1143-1168.

Flum, H., \& Cinamon, R. G. (2011). Immigration and the interplay among citizenship, identity and career: The case of Ethiopian immigration to Israel. Journal of Vocational Behavior, 78(3), 372-380.

Forkosh-Baruch, A., \& Hershkovitz, A. (2012). A case study of Israeli higher-education institutes sharing scholarly information with the community via social networks. The Internet and Higher Education, 15(1), 58-68.

Goldblatt, H., \& Rosenblum, S. (2007). Navigating among worlds: The experience of Ethiopian adolescents in Israel. Journal of Adolescent Research, 22(6), 585-611.

Greene, T. G., Marti, N., \& McClenney, K. (2008) Differences for African American and Hispanic community college students in student engagement and academic achievement. The Journal of Higher Education, 79(5), 513-539.

Hustad, E., \& Arntzen, A. A. B. (2013). Facilitating teaching and learning capabilities in social learning management systems: Challenges, issues, and implications for design. Journal of Integrated Design and Process Science, 17(1), 17-35.

Israel's Central Bureau of Statistics. (2010). Higher education in Israel. Jerusalem, Israel. Retrieved from http://www.cbs.gov.il/publications10/m1388_haskhala_gvoha08/pdf/h_print.pdf(in Hebrew).

Israel's Central Bureau of Statistics. (2011). Statistical abstract of Israel 2011. Jerusalem, Israel. (in Hebrew).

Israel's Central Bureau of Statistics. (2013). The Ethiopian population in Israel. Jerusalem, Israel. Retrieved from http://www.cbs.gov.il/reader/cw_usr_view_SHTML?ID=629 (In Hebrew).

Jürgens, P. (2012). Communities of communication: Making sense of the "social" in social media. In K. Bredl, J. Hünniger, \& J. L. Jensen (Eds.), Methods for analyzing social media (pp. 45-62). London and New York: Taylor \& Francis Group.

Kali, Y. (2008). The design principles database as means for promoting design-based research. Handbook of design research methods in education, 423-438.

Kali, Y., Tabak, I., Ben-Zvi, D., Kidron, A., Amzaleg, M., Baram-Tsabari, A., ... Kirschner, P. (2015). Technology-enhanced learning communities on a continuum between ambient to designed: What can we learn by synthesizing multiple research perspectives? Proceedings of the Computer Supported Collaborative Learning (CSCL) conference, Gothenburg 2015.

Kapur, M. (2014). Productive failure in learning math. Cognitive Science, 38(5), 1008-1022.

King, J., Fishman, N., \& Wolde-Tsadick, A. (2012). Twenty years later: A survey of Ethiopian immigrants who have lived in Israel for two decades or more. Jerusalem, Israel: Myers-JDC-Brookdale Institute.

Kurtz, G. (2014). Integrating a Facebook group and a course website: The effect on participation and perceptions on learning. American Journal of Distance Education, 28(4), 253-263.

Lauricella, S., \& Kay, R. (2013). Exploring the use of text and instant messaging in higher education classrooms. Research in Learning Technology, 21, 2-18.

Lave, J., \& Wenger, E. (1991). Situated learning: Legitimate peripheral participation. Cambridge University Press.

LINKS. (2012). Learning In a NetworKed Society (LINKS): Co-creation of knowledge in technologyenhanced learning communities. Unpublished research proposal.

Madge, C., Meek, J., Wellens, J., \& Hooley, T. (2009). Facebook, social integration and informal learning at university: 'It is more for socialising and talking to friends about work than for actually doing work'. Learning, Media and Technology, 34(2), 141-155. 
Meishar-Tal, H., Kurtz, G., \& Pieterse, E. (2012). Facebook groups as LMS: A case study. The International Review of Research in Open and Distance Learning, 13(4), 33-48.

Mendelson-Maoz, A. (2013). Diaspora and Homeland - Israel and Africa in beta Israel's Hebrew literature and culture. Research in African Literatures, 44(4), 35-50.

Mesch, G. S. (2012). Minority status and the use of computer-mediated communication: A test of the social diversification hypothesis. Communication Research, 39(3), 317-337.

Mizrachi, N., \& Herzog, H. (2012). Participatory destigmatization strategies among Palestinian citizens, Ethiopian Jews and Mizrahi Jews in Israel. Ethnic and Racial Studies, 35(3), 418-435.

Myers-JDC-Brookdale Institute. (2012). The Ethiopian-Israeli community: Facts and figures. Research report.

Nonnecke, B., \& Preece, J. (2001). Why lurkers lurk. Paper presented at the AMCIS conference. Boston, MA.

Özgüven, N., \& Mucan, B. (2013). The relationship between personality traits and social media use. Social Behavior and Personality, 41(3), 517-528.

Peeters, A. L., \& d'Haenens, L. (2005). Bridging or bonding? Relationships between integration and media use among ethnic minorities in the Netherlands. Communications, 30(2), 201-231.

Preece, J., Nonnecke, B., \& Andrews, D. (2004). The top five reasons for lurking: Improving community experiences for everyone. Computers in Human Behavior, 20(2), 201-223.

Putnam, R. D. (1993). The prosperous community: Social capital and public life. The American Prospect, 4(13), 35-42.

Putnam, R. D. (2001). Bowling alone: The collapse and revival of American community. Simon and Schuster.

Quan-Haase, A., \& Young, A. L. (2010). Uses and gratifications of social media: A comparison of Facebook and instant messaging. Bulletin of Science, Technology \& Society, 30(5), 350-361.

Rafaeli, S., Ravid, G., \& Soroka, V. (2004). De-lurking in virtual communities: A social communication network approach to measuring the effects of social and cultural capital. In System Sciences, 2004. Proceedings of the 37th Hawaii International Conference on System Sciences. Los Alamitos, CA: IEEE Press.

Rau, P-L. P., Gao, Q., \& Ding, Y. (2008). Relationship between the level of intimacy and lurking in online social network services. Computers in Human Behavior, 24, 2757- 2770.

Ringel, S., Ronell, N., \& Getahune, S. (2005). Factors in the integration process of adolescent immigrants: The case of Ethiopian Jews in Israel. International Social Work, 48(1), 63-76.

Rosenblum, S., Goldblatt, H., \& Moin, V. (2008). The hidden dropout phenomenon among immigrant high-school students. The case of Ethiopian adolescents in Israel-A pilot study. School Psychology International, 29(1), 105-127.

Saguy, T., \& Chernyak-Hai, L. (2012). Intergroup contact can undermine disadvantaged group members' attributions to discrimination. Journal of Experimental Social Psychology, 48(3), 714-720.

Salamon, H. (2003). Blackness in transition: Decoding racial constructs through stories of Ethiopian Jews. Journal of folklore research, 40(1), 3-32.

Sandoval, W. (2014). Conjecture mapping: An approach to systematic educational design research. Journal of the Learning Sciences, 23(1), 18-36.

Schejter, A., \& Tirosh, N. (2014). New media policy: The redistribution of voice. In Y. Liu \& R. Picard (Eds.), Policy and marketing strategies for digital media (pp. 73-86). London: Routledge.

Shabtay, M. (2003). 'RaGap': Music and identity among young Ethiopians in Israel. Critical Arts, 17(1-2), 93-105. 
Shaviv, M., Binstein, N., Stone, A., \& Fudem, O. (2013). Pluralism and equal opportunity in higher education expanding access for Arabs, Druze and Circassians in Israel. Jerusalem, Israel: Council for Higher Education. Retrieved from http://che.org.il/wp-content/uploads/2013/03/Pluralism-and-equalopportunities-in-higher-education-FINAL.pdf

Song, H. A., \& Elliott, W. (2011). The role of assets in improving college attainment among Hispanic immigrant youth in the US. Children and Youth Services Review, 33(11), 2160-2167.

Steinfield, C., Ellison, N. B., \& Lampe, C. (2008). Social capital, self-esteem, and use of online social network sites: A longitudinal analysis. Journal of Applied Developmental Psychology, 29(6), 434-445.

Tobin, S. J., Vanman, E. J., Verreynne, M., \& Saeri, A. K. (2015). Threats to belonging on Facebook: Lurking and ostracism. Social Influence, 10(1), 31-42.

Vurgan, Y. (2011). The dropout rates of students in the education system. Jerusalem, Israel: The Knesset, Research and Information Center. Retrieved from https://www.knesset.gov.il/mmm/data/pdf/m02962.pdf (in Hebrew).

Walsh, S. D., \& Tuval-Mashiach, R. (2012). Ethiopian emerging adult immigrants in Israel coping with discrimination and racism. Youth \& Society, 44(1), 49-75

Windzio, M. (2012). Integration of immigrant children into Inter- ethnic friendship networks: The role of “intergenerational openness". Sociology, 46(2), 258-271.

Yu, B., \& Shen, H. (2012). Predicting roles of linguistic confidence, integrative motivation and second language proficiency on cross-cultural adaptation. International Journal of Intercultural Relations, 36(1), $72-82$.

\section{Biographies}

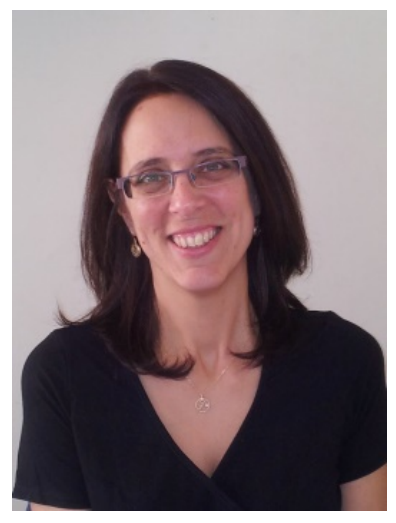

Meital Amzalag completed her B.Sc in the Department of Chemistry at the Faculty of Natural Science at the Hebrew University and her MA in the School of Education at Tel-Aviv University. She is currently a $\mathrm{Ph} . \mathrm{D}$ student in the Faculty of Education at the University of Haifa and a member of the Learning In a NetworKed Society (LINKS) Israeli Center of Research Excellence (I-CORE). Meital is the head of the Department of computers in Ruppin Technological College. She is also a lecturer at the Ruppin Academic Center and at the College for Academic Studies.

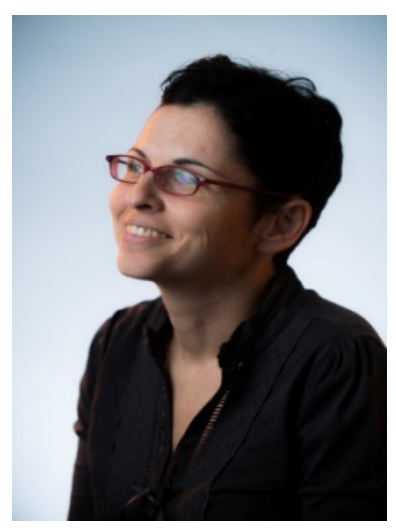

Nelly Elias (Ph.D.) is an Associate Professor at the Department of Communication Studies, Ben-Gurion University of the Negev, Israel. Among her main research interests are media and ethnic minorities and media and children. Recently she has joined the 'Learning in a NetworKed Society (LINKS)' - Israeli Center of Research Excellence. Within the center she is conducting a series of projects on the toddlers' media uses in the changing technological environment. Nelly Elias is an author of Coming Home: Media and Returning Diaspora in Israel and Germany (SUNY Press) and a co-editor of Media and Ethnic Minorities in the Holy Land (Vallentine Mitchell). She has published extensively in leading academic journals in English, Russian and Hebrew. 


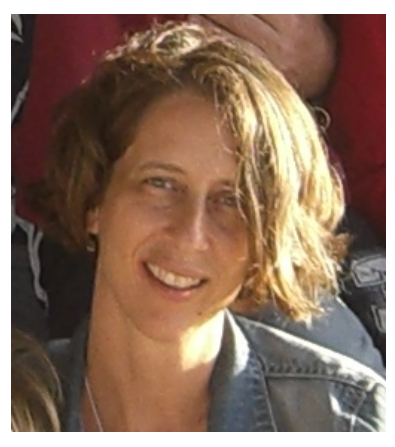

Yael Kali is an associate professor of technology-enhanced learning at the Technologies in Education Graduate Program, Faculty of Education, University of Haifa, and the director of the Learning In a NetworKed Society (LINKS) Israeli Center of Research Excellence (ICORE). Using a design-based research approach, Kali explores technology-enhanced learning and teaching at various levels, from junior high school to higher education. Together with her students of the TEL Design group she studies the role of design, and design principles for supporting Computer Supported Collaborative Learning (CSCL), and for teacher professional development, in a Teachers as Designers

(TaD) approach. Kali currently serves as an Associate Editor for the journal Instructional Science. 